\title{
Ecologically-friendly operation scheme for the Jinping cascaded reservoirs in the Yalongjiang River, China
}

\author{
Duan CHEN ${ }^{1,2}$, Qiuwen CHEN $(\bowtie)^{1,3}$, Ruonan LI $^{1}$, Koen BLANCKAERT ${ }^{1}$, Desuo CAI ${ }^{4}$ \\ 1 Research Center for Eco-Environmental Sciences, Chinese Academy of Sciences, Beijing 100085, China \\ 2 Changjiang River Scientific Research Institute, Wuhan 430010, China \\ 3 Nanjing Hydraulics Research Institute, Nanjing 210023, China \\ 4 Guangxi Water Conservancy Department, Nanning 530023, China
}

(C) Higher Education Press and Springer-Verlag Berlin Heidelberg 2013

\begin{abstract}
Ecologically-friendly reservoir operation procedures aim to conserve key ecosystem properties in the rivers, while minimizing the sacrifice of socioeconomic interests. This study focused on the Jinping cascaded reservoirs as a case study. An optimization model was developed to explore a balance between the ecological flow requirement (EFR) of a target fish species (Schizothorax chongi) in the dewatered natural channel section, and annual power production. The EFR for the channel was determined by the Tennant method and a fish habitat model, respectively. The optimization model was solved by using an adaptive real-coded genetic algorithm. Several operation scenarios corresponding to the ecological flow series were evaluated using the optimization model. Through comparisons, an optimal operational scheme, which combines relatively low power production loss with a preferred ecological flow regime in the dewatered channel, is proposed for the cascaded reservoirs. Under the recommended scheme, the discharge into the Dahewan river reach in the dry season ranges from 36 to $50 \mathrm{~m}^{3} / \mathrm{s}$. This will enable at least $50 \%$ of the target fish habitats in the channel to be conserved, at a cost of only $2.5 \%$ annual power production loss. The study demonstrates that the use of EFRs is an efficient approach to the optimization of reservoir operation in an ecologically friendly way. Similar modeling, for other important fish species and ecosystem functions, supplemented by field validation of results, is needed in order to secure the long-term conservation of the affected river ecosystem.
\end{abstract}

Keywords ecologically-friendly operation, optimization model, ecological flow, Jinping cascaded reservoirs, Schizothorax chongi

Received March 8, 2013; accepted May 26, 2013

E-mail: qchen@rcees.ac.cn

\section{Introduction}

Ecologically-friendly reservoir operation aims to conserve the key ecosystem features of a river regulated by large dams, emphasizing the flow regime, while sustaining socioeconomic interests (Suen and Eheart, 2006; Smith et al., 2007). The Jinping (JP) cascaded reservoirs, including JP-1 and JP-2, are located in the lower Dahewan Reach of the Yalongjiang River. They are constructed mainly for hydropower generation. JP-1 has a $305 \mathrm{~m}$ high concrete dam with a power plant situated at the toe of the dam. JP-2 is located immediately downstream of the JP-1 reservoir. The dam of JP-2 is much lower, but nearly $310 \mathrm{~m}$ of energy head was provided by creating shortcuts through four diversion tunnels, that eliminated a $120 \mathrm{~km}$ long loop in the natural river. The power plant of JP-2 is located at the end of the diversion tunnels. The configuration of the reservoir networks is depicted in Fig. 1. Under the current operation of the reservoirs, the flow in the $120 \mathrm{~km}$ long natural channel (the Dahewan Reach) will be reduced dramatically, due to water extraction to the tunnels. Water depth and flow velocity will decrease substantially, and some sections may even dry up during the dry season (Chen et al., 2013).

The year 2001 was a typical normal flow year. The annual average discharge at the Maomaotan hydrological station, which is the control point of the Dahewan Reach, is $1220 \mathrm{~m}^{3} / \mathrm{s}$. The river width of the Dahewan Reach ranges from $70 \mathrm{~m}$ to $110 \mathrm{~m}$. While riparian vegetation is rare, due to steep slopes and very coarse bed materials, there is rich algal aquatic vegetation, including Bacillariophyta and Chlorophyta, which supports a rich benthic invertebrate fauna. Also, 38 fish species are found in the river reach, and some of them are listed in the provincial protection catalogue. Particularly, the area addressed in this study includes lots of spawning and over-wintering grounds of 
an important indigenous fish, Schizothorax chongi ( $S$. chongi) (Fig. 1).

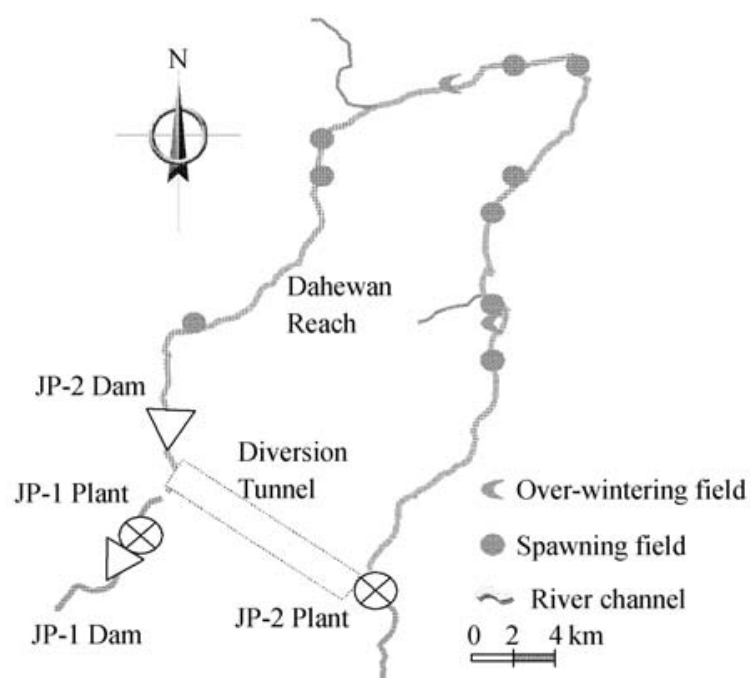

Fig. 1 Sketch of the JP cascade project together with overwintering and spawning fields of Schizothorax chongi fish in the Dahewan Reach.

River ecosystems are known to be strongly dependent on hydrological regimes (Whiting, 2002; Wohl et al., 2005; Yang et al., 2009). The operation of the JP cascaded reservoirs would alter the natural hydrological regime in the Dahewan Reach substantially, and thus, impose severe impacts on the river ecosystem, especially on the fish habitat (Richter et al., 1997; Li et al, 2011). To protect the river ecosystem, conventional operations need to be adapted to account for ecological flow requirements (Jager and Rose, 2003; Renöfält et al., 2010). An ecologically adapted flow regime requires that a certain minimum discharge must be released into the Dahewan Reach, to maintain the habitat of the biota.

Ecologically-friendly reservoir operation aims to preserve habitat conditions in downstream sections as much as possible (Homa et al., 2005; Chen et al., 2012). However, the major function of the JP cascaded reservoirs is hydropower production. The release of ecological flow unavoidably leads to a loss of hydropower generation (Shiau and Wu, 2006; Chen et al., 2009). Therefore, the target of ecologically-friendly operation of the JP cascaded reservoirs is, to quantify the loss of power generation, and to find an optimal scheme that largely satisfies the ecological flow requirement while minimizing the loss of hydropower production.

In this study, an optimization model for the ecologicallyfriendly operation of the JP cascaded reservoirs is developed, which considers the ecological flow requirement (EFR) to be a dynamic constraint. Both the Tennant and the habitat methods are used to determine the EFR of the Dahewan Reach. An adaptive real-coded genetic algorithm was employed to obtain optimal solutions.
Several scenarios were analyzed to quantify the relations between the degree of satisfaction of EFR and rate of power loss. An optimal operation strategy that has an acceptable trade-off between EFR satisfaction and power production is finally recommended.

\section{Optimization model for ecologically- friendly operation of cascaded reservoirs}

Optimization models for conventional reservoir operations generally consist of an objective function, constraints, and an optimization technique. General descriptions on the subject can be found in Labadie (2004) and Castelletti et al. (2008). Optimization models for ecologically-friendly reservoir operation were further proposed by taking into account the EFR of the downstream reach (Wurbs, 1993; Homa et al., 2005). The EFR can be added as an additional constraint in the optimization model (Castelletti et al., 2008), or as another objective supplementing economic objectives (Yin and Yang, 2011). In this study, the EFR is considered as an additional constraint.

\subsection{Objective function}

According to the core purpose of the two reservoirs, the annual hydropower generation is considered as the objective function, given in Eq. (1).

$$
P=\max \left(\sum_{t=1}^{n}\left(e^{1} Q_{d, t}^{1} \bar{H}_{t}^{1}+e^{2} Q_{d, t}^{2} \bar{H}_{t}^{2}\right) T_{t}\right),
$$

where $P$ is total annual hydropower $(\mathrm{kWh}) ; e$ is power plant efficiency (determined by the turbines); $Q_{d}$ is release through turbines $\left(\mathrm{m}^{3} / \mathrm{s}\right) ; \bar{H}$ is averaged water head $(\mathrm{m}) ; t$ is time step; $T$ is the number of operation hours for power plant and reservoir in time step; $n$ is length of the operation time. The notations 1 and 2 represent JP-1 and JP-2, receptively.

\subsection{Constraints}

\subsubsection{General constraints}

Reservoir mass balance equation:

$$
\frac{\mathrm{d} V}{\mathrm{~d} t}=Q_{n, t}-Q_{u p, t}-Q_{l o s s, t}-Q_{d, t}-S_{t} .
$$

This equation was transformed into discrete equations (for JP-1 and JP-2 reservoirs) as follows for iteration:

$$
\begin{array}{r}
V_{t+1}^{1}-V_{t}^{1}=\left(Q_{n, t}^{1}-Q_{u p, t}^{1}-Q_{l o s s, t}^{1}-Q_{d, t}^{1}-Q_{s, t}^{1}\right) T, \\
V_{t+1}^{2}-V_{t}^{2}=\left(Q_{d, t}^{1}+Q_{s, t}^{1}-Q_{u p, t}^{2}-Q_{l o s s, t}^{2}-Q_{d, t}^{2}-Q_{s, t}^{2}\right) T .
\end{array}
$$

\footnotetext{
Reservoir storage constraints:
} 


$$
V_{d}^{1,2} \leqslant V_{t}^{1,2} \leqslant V_{m}^{1,2} .
$$

Turbine release constraints:

$$
0 \leqslant Q_{d, t}^{1,2} \leqslant Q_{d, \max }^{1,2}
$$

Plant output constraints:

$$
N_{f}^{1,2} \leqslant N_{t}^{1,2} \leqslant N_{i}^{1,2}
$$

Water level variation constraints:

$$
\left|\bar{H}_{t}^{1}-\bar{H}_{t+1}^{1}\right| \leqslant \delta,
$$

where $V$ is water volume in the reservoir $\left(\mathrm{m}^{3}\right) ; S_{t}$ is release through other structures except turbines $\left(\mathrm{m}^{3} / \mathrm{s}\right) ; Q_{n}$ is inflow from upstream $\left(\mathrm{m}^{3} / \mathrm{s}\right) ; Q_{u p}\left(\mathrm{~m}^{3} / \mathrm{s}\right)$ is water withdrawn from the reservoir; $Q_{\text {loss }}\left(\mathrm{m}^{3} / \mathrm{s}\right)$ is water loss by evaporation and leakage; $V_{d}\left(\mathrm{~m}^{3}\right)$ is dead storage; $V_{m}\left(\mathrm{~m}^{3}\right)$ is reservoir maximum capacity $\left(\mathrm{m}^{3}\right) ; Q_{t}\left(\mathrm{~m}^{3} / \mathrm{s}\right)$ is release through the turbines for power generation; $Q_{d, \text { max }}\left(\mathrm{m}^{3} / \mathrm{s}\right)$ is turbine capacity; $N_{t}(\mathrm{~kW})$ is output of power plant; $N_{f}(\mathrm{~kW})$ is firm output; $N_{i}(\mathrm{~kW})$ is installed capacity; and $\delta$ is a threshold of variation of reservoir water level (m).

\subsubsection{Ecological constraints}

The ecological constraint in this study is the EFR in the Dahewan Reach. Most of the previous studies considered ecological flow needs by incorporating a hard constraint of a constant minimum flow rate (Homa et al, 2005). However such treatment has encountered serious argument, because in-stream flow requirements are far more complex than a fixed aquatic base flow requirement (Shiau and $\mathrm{Wu}, 2006$; Smith et al., 2007).

In this study, a flow process $\left(Q_{e, t}\right)$ is employed as a dynamic constraint on ecological flow. The $Q_{e, t}$ is timevarying, in order to account for seasonal changes of the natural flow regime, as well as to account for varying requirements of the target species in its various life stages. The EFR constraint would cause an additional loss of hydropower production on the system. To explore the relation between degree of satisfaction of ecological flow and hydropower production loss, a slack variable $\lambda$ is introduced to the constraint. The slack variable allows a relationship to be established between the $Q_{e, t}$ constraint and the corresponding hydropower losses by running the model repeatedly. The constraints are set as follows:

$$
\begin{gathered}
Q_{d, t}^{1}+S_{t}^{1} \geqslant \lambda \cdot Q_{e, t}, \\
Q_{d, t}^{1}+S_{t}^{1}-Q_{d, t}^{2}=\lambda \cdot Q_{e, t},
\end{gathered}
$$

where: $Q_{d, t}^{1}$ and $Q_{d, t}^{2}$ are release through turbines of the JP-1 and JP-2, respectively; $Q_{e, t}$ is the ecological flow process required in the Dahewan Reach; $\lambda$ is the slack variable, bounded in $[0,1]$.

\subsection{Decision variable}

The reservoir water level is usually used for reservoir operation and was selected to be the decision variable in the optimization model. The JP-1 reservoir is an annual regulation reservoir, whereas the JP-2 reservoir is a daily regulation reservoir. In order to derive a daily operation scheme, a daily-based optimization model is proposed. Thus, the time step $t$ in the model is one day. For a year, $n$ becomes 365 . There are 730 independent variables, in total, for the two reservoirs.

\subsection{Optimization techniques}

Plenty of techniques for solving reservoir optimization models have been proposed, including linear programming, dynamic programming, genetic algorithm, gradientbased searching, and heuristic programming (Yeh, 1985; Wurbs, 1993; Labadie, 2004). In this study, a genetic algorithm (GA) is used to seek optimal solutions of the optimization model. To deal effectively with multiple nonlinear constraints in the optimization of reservoir operation, an adaptive real-coded genetic algorithm (ARGA) was employed in this study (Chen et al., 2010). This method shows significant improvements in efficiency and accuracy, when compared to conventional GA, and it also decreases the probability of local optimal.

The general procedure of ARGA (Fig. 2) starts with an initial randomly generated population of reservoir water levels. Then, through iterations, the procedure approaches optimal solutions by implementing GA operators, including selection, crossover and mutation. The procedure continues until a suitable solution is found or a certain number of iterations have been reached.

\subsection{Model inputs}

The practical objective of this study is to outline a general guide for the operation of the Jinping cascaded reservoirs that can efficiently balances human interests and the ecological requirements of river flow. Therefore, deterministic data from observations instead of stochastic data from hydrological forecasting are used as model inputs. The hydrological data of 2001, a typical normal flow year, is selected. In this case, the model has 730 decision variables, $\left[H_{1}^{1}, H_{2}^{1}, \ldots, H_{365}^{1} ; H_{1}^{2}, H_{2}^{2}, \ldots, H_{365}^{2}\right], 2,920$ dependent variables for $V, S, Q_{d}, N$, and 15,530 constraints. Although the use of deterministic data is more computationally efficient than stochastic optimization (Labadie, 2004), it should be noted that real-time predictions of river inflows, that involve stochastic components, should be applied to practical operations.

\section{Determination of ecological flows}

There are a variety of methods available for defining 


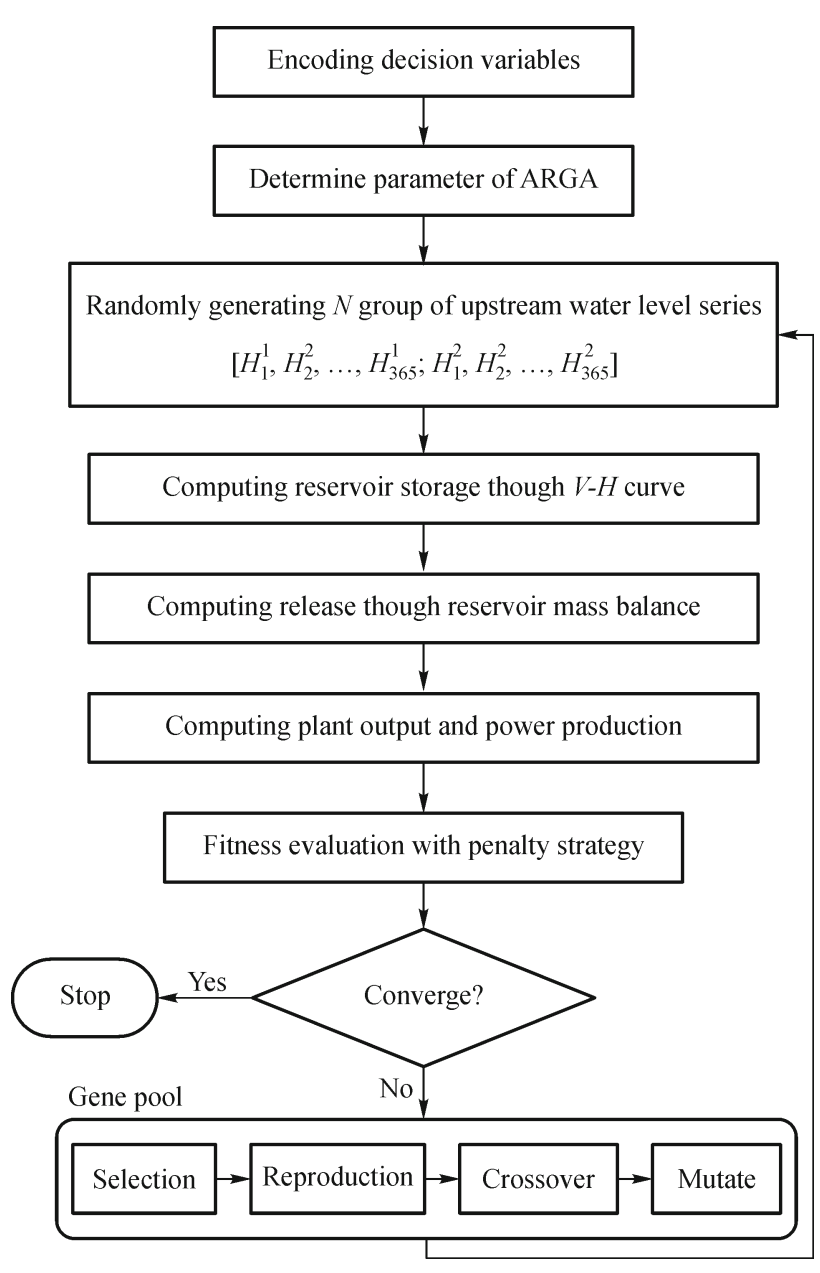

Fig. 2 Flowchart of the GA optimization procedure.

dynamic in-stream flow requirements (Richter et al., 1997; Tharme, 2003; Shiau and Wu, 2006; Li et al., 2011). These include hydrological methods, hydraulic methods, habitat models and holistic methods. In this study, the widely used Tennant method (hydrological method) and the habitat method are applied to determine the EFR in the Dahewan Reach, in order to attain targeted ecological constraints.

\subsection{Determining ecological flow with the Tennant method}

The Tennant method (Tennant, 1976), also known as the 'Montana' method, is perhaps the most widely known hydrological method. Because it is rather simple and easy to apply, the method is recognized by 16 states in the United States for defining ecological flow needs (Reiser et al., 1989), and it has also been applied in at least twentyfour other countries. The Tennant method assumes that some percentage of the mean flow of a river is needed to maintain a healthy stream environment. After examining cross-section data such as width, water velocity, and depth of 11 streams in Montana, Nebraska and Wyoming, Tennant suggested that $60-100$ percent of a river's average flow would need to be protected in order to sustain 'optimum' biological conditions. However, to provide 'excellent habitat', only 30-50 percent of the flow might be needed. There are also other definitions of flow rates necessary to maintain corresponding quality of the habitat (Tennant, 1976). Generally speaking, the Tennant method provides a basic evaluation between the percent of a river's average flow and the corresponding river management target (defined as narrative description of flows), such as optimum and excellent. For details of the Tennant method, refer to Tennant (1976).

In our case, the average flow in the Dahewan Reach is $1,220 \mathrm{~m}^{3} / \mathrm{s}$, with a flooding season generally lasting from June to October. Most of the fish in that area normally start to spawn in early June. The flow requirements of the river ecosystem were evaluated according to the Tennant method and are listed in Table 1. To quantify the relation between the river management target and power generation, the narrative description of flows in Table 1 are also given in percentages of natural monthly average flow. This was calculated by averaging the percentages for the dry season and the flood season, which are in fact slightly different with the Tennant method. For example, the percentages in dry season and flood season for 'outstanding' flow in the Tennant method are $40 \%$ and $60 \%$ respectively. In this study, the two percentages were averaged into one percentage, $50 \%$, as shown in Table 1 , for one-to-one correspondence with power generation.

\subsection{The ecological flow by Habitat model}

Habitat methods have developed rapidly in recent decades. They consider both flow condition and biological reaction, and define ecological flow requirement by specific habitat conservation. Weighted usable area (WUA) is widely used in habitat methods. WUA is defined as the total surface area having a certain combination of hydraulic conditions, multiplied by the composite probability of use for that combination of conditions (Bovee, 1982). Although much more field observation data are required by these methods, advanced survey technologies easily overcome this issue.

In the studied case, $S$. chongi is the dominant fish species in the dewatered reach, accounting for $15.2 \%$ of the total Cyprinidae fish in the investigated area. It was selected as the target species for the study. The habitat model developed by Li et al. (2011), for the target fish S. chongi in the river reach, was introduced to define the ecological flow requirements. The model is a multi-input and singleoutput fuzzy system, comprising of 3 input and 1 output variables. The inputs are water depth, velocity, and water temperature. The output is habitat suitability index (HSI). The membership degree functions and fuzzy inference rules were initially set up based on the results of flume experiments (Tu et al, 2011). Field investigation data and partial flume experiment data were used to improve the membership degree functions and the rule sets. For each flow, HSI and then WUA were calculated for every cell of 
Table 1 Habitat status and corresponding discharges into the Dahewan Reach using the Tennant method

\begin{tabular}{|c|c|c|c|c|c|c|c|c|c|c|c|c|c|}
\hline Narrative description of flows & $\%$ of the average flow & Jan & Feb & Mar & Apr & May & Jun & July & Aug & Sept & Oct & Nov & $\overline{\text { Dec }}$ \\
\hline Severe degradation & 0 & 0 & 0 & 0 & 0 & 0 & 0 & 0 & 0 & 0 & 0 & 0 & 0 \\
\hline Poor & 5 & 61 & 61 & 61 & 61 & 61 & 61 & 61 & 61 & 61 & 61 & 61 & 61 \\
\hline Fair & 15 & 122 & 122 & 122 & 122 & 122 & 244 & 244 & 244 & 244 & 244 & 122 & 122 \\
\hline Good & 30 & 244 & 244 & 244 & 244 & 244 & 488 & 488 & 488 & 488 & 488 & 244 & 244 \\
\hline Excellent & 40 & 366 & 366 & 366 & 366 & 366 & 610 & 610 & 610 & 610 & 610 & 366 & 366 \\
\hline Outstanding & 50 & 488 & 488 & 488 & 488 & 488 & 732 & 732 & 732 & 732 & 732 & 488 & 488 \\
\hline Optimum range & 100 & 358 & 321 & 328 & 435 & 695 & 1,590 & 2,810 & 2,590 & 2,500 & 1,620 & 809 & 488 \\
\hline
\end{tabular}

Note: the 'Optimum range' in the table is defined as natural average flow.

the studied area. Thus, the curve of discharge $(Q)$ versus WUA could be established. The WUA corresponding to the natural hydrograph in the normal flow year was used as a reference point; and then the EFRs in relation to different habitat conservation levels at specific fish life stages were obtained through inverse calculation.

Using the model, the different flow requirements under the corresponding proportion of habitat conservation for $S$. chongi fish are derived and listed in Table 2.

\section{Results}

\subsection{Based on the Tennant method}

The various scenarios according to the Tennant method are summarized in Table 3. Scenario T1 means no consideration of ecological aspects in reservoir operation, while T7 is the scenario where the ecological flow reaches the level of the natural average flow in the Dahewan, i.e., the $\lambda$ in the EFR constraint is 1 . The other scenarios lie in the range between $\mathrm{T} 1$ and $\mathrm{T} 7$, where ecological flows are satisfied to an extent ranging from $5 \%$ to $50 \%$.

The operation scenarios that consider ecological flow will unavoidably lead to hydropower production loss. We define power generation under conventional operation (means no EFR constraint) as the maximum possible value $P_{0}$, while power generation under ecologically-friendly operation is $P_{\mathrm{n}}$. The rate of power loss in each scenario of ecologically-friendly operation is then calculated as $\left(P_{0^{-}}\right.$ $\left.P_{\mathrm{n}}\right) / P_{0}$. The various discharge series in Table 1 have been used as ecological constraints; and the corresponding loss rate of power production has been calculated by the optimization model. The results are shown in Table 3.

Scenario T1 represents conventional operation without EFR constraint, so it is set as the benchmark. The loss rate gradually increases with the improvement of the ecological status of the river reach according to the narrative

Table 2 Habitat status and corresponding discharge in the Dahewan Reach using the habitat model

\begin{tabular}{lcccccccccccc}
\hline Percentage of WUA & Jan & Feb & Mar & Apr & May & Jun & July & Aug & Sept & Oct & Nov & Dec \\
\hline $0 \%$ & 0 & 0 & 0 & 0 & 0 & 0 & 0 & 0 & 0 & 0 & 0 & 0 \\
$10 \%$ & 3 & 3 & 3 & 22 & 24 & 31 & 33 & 32 & 59 & 57 & 4 & 3 \\
$20 \%$ & 7 & 6.5 & 6.7 & 43 & 48 & 65 & 69 & 68 & 108 & 104 & 7 & 7 \\
$30 \%$ & 13 & 12 & 12 & 68 & 75 & 107 & 113 & 113 & 159 & 152 & 13 & 13 \\
$40 \%$ & 22 & 21 & 21 & 96 & 107 & 159 & 169 & 168 & 217 & 206 & 24 & 23 \\
$50 \%$ & 40 & 36 & 38 & 110 & 112 & 152 & 108 & 169 & 168 & 158 & 38 & 50 \\
$60 \%$ & 64 & 61 & 62 & 167 & 192 & 304 & 328 & 326 & 377 & 351 & 69 & 68 \\
$70 \%$ & 78 & 74 & 75 & 201 & 217 & 252 & 186 & 313 & 310 & 261 & 75 & 98 \\
$80 \%$ & 139 & 128 & 130 & 271 & 323 & 556 & 625 & 620 & 734 & 644 & 157 & 156 \\
$90 \%$ & 225 & 168 & 170 & 330 & 342 & 366 & 288 & 1,240 & 1,230 & 850 & 170 & 370 \\
$100 \%$ & 358 & 321 & 328 & 435 & 695 & 1,590 & 2,810 & 2,590 & 2,500 & 1,620 & 809 & 488 \\
\hline
\end{tabular}

Note: $100 \%$ in the table is defined as one under the natural average flow.

Table 3 Operation schemes constrained by the eco-hydrograph from the Tennant method

\begin{tabular}{|c|c|c|c|c|c|c|c|}
\hline Narrative description of flows & Severe degradation & Poor & Fair & Good & Excellent & Outstanding & Optimum range \\
\hline Satisfaction degree of EFR & $0 \%$ & $5 \%$ & $15 \%$ & $30 \%$ & $40 \%$ & $50 \%$ & $100 \%$ \\
\hline Scenario notation & $\mathrm{T} 1$ & $\mathrm{~T} 2$ & $\mathrm{~T} 3$ & $\mathrm{~T} 4$ & $\mathrm{~T} 5$ & T6 & $\mathrm{T} 7$ \\
\hline Power loss rate & $0.0 \%$ & $-5.0 \%$ & $-9.1 \%$ & $-12.7 \%$ & $-18.1 \%$ & $-21.1 \%$ & $-39.4 \%$ \\
\hline
\end{tabular}

Note: the 'Optimum range' in the table is defined as the natural average flow. 
description of its flows (Fig. 3). When the EFR satisfaction is $5 \%$, there will be 5\% loss of power production in comparison to the conventional operation. It will reach almost $40 \%$ when the EFR satisfaction is $100 \%$.



Fig. 3 Relation between percentage of average flow and power production loss.

\subsection{Based on Habitat method}

The various discharge series shown in Table 2, which represent varying conservation rates of $S$. chongi habitat, are used as ecological constraints. The corresponding loss rate of power production was calculated using the optimization model. The results are shown in the Table 4 and Fig. 4. The loss rate of power production increases with higher WUA targets. If $30 \%$ of the WUA is conserved, there will be $1.5 \%$ loss of power production. However, a knick point can be found at the $50 \%$ WUA conservation level, at the expense of only $2.5 \%$ hydropower loss. Increasing the WUA from $50 \%$ to $90 \%$ is relatively more expensive, bringing an additional $37 \%$ loss of hydropower production. Conservation of $100 \%$ WUA would result in $40 \%$ loss of hydropower production, the same as was calculated using the Tennant method.

\section{Discussion}

5.1 Discussion of an optimal operation strategy for the Jinping cascaded reservoirs

The objective of ecologically-friendly reservoir operation in the Yanglong River is 'to maintain the original interest of reservoirs, and to mitigate their negative impact on the ecosystem as much as possible' (Wang, 2004). Therefore, the optimal strategy for reservoir operation should be the one with minimal loss of socioeconomic interest, but with maximum ecosystem conservation. Due to the difficulty of quantifying the value of ecosystems, 'Narrative description of flows' and the WUA of target fish have been introduced in this study. In any case, the ecological flow released to the dewatered river reach must be sufficient to meet the flow requirements of a viable population of the target fish species. The results, based on the habitat method, indicate that an optimal point, corresponding to good ecosystem status and reduced loss of human interests, can be found for reservoir operations. However, there is no such optimal solution evident when the scenarios were evaluated based on the Tennant method.

Several relevant studies have been done about this case. For the EFR in the Dahewan reach, Li et al. (2011) used a so-called eco-hydraulic method, and pointed out that 45 $\mathrm{m}^{3} / \mathrm{s}$ of flow in the dry season could satisfy the needs of the fish. Wang and Guo (2011) implemented a hydraulic method, and also concluded that $45 \mathrm{~m}^{3} / \mathrm{s}$ of flow can meet most hydraulic parameters for maintaining the ecosystem of the river reach. For the operation of the JP cascaded reservoirs, Mei et al. (2009) considered five constant EFRs that range from $36 \mathrm{~m}^{3} / \mathrm{s}$ to $120 \mathrm{~m}^{3} / \mathrm{s}$ in an optimization model, and compared their impacts on hydropower generation. The results implied that hydropower loss increased sharply along with the improvement of EFR.

In this study, the reservoir operation scenarios based on the habitat method have strong pertinence. The flow requirements at typical life stages of $S$. chongi fish are considered. Meanwhile the power loss of $2.5 \%$ is relatively acceptable to the water manager. Therefore, the proposed optimal strategy for the ecologically-friendly reservoir operation of the the JP cascaded reservoir project is recommended, in order to conserve 50\% WUA of the target fish.

5.2 Discussion of the operational hydrograph under the optimal strategy

Under the proposed optimal strategy, the operational hydrograph on reservoir water level and the corresponding releases can be obtained using the optimization model. The reservoir water levels are shown in Fig. 5, and the corresponding releases from JP-1 and JP-2 are shown in Figs. 6 and 7, respectively.

According to the general plan of reservoir operations

Table 4 Operation schemes constrained by the eco-hydrograph from habitat method

\begin{tabular}{lcccccc}
\hline Percentage of WUA & $0 \%$ & $30 \%$ & $50 \%$ & $70 \%$ & $90 \%$ & H5 \\
\hline Scenario notation & H1 & H2 & H3 & H4 & H6 \\
Power loss rate & $0.0 \%$ & $-1.5 \%$ & $-2.5 \%$ & $-4.9 \%$ & $-15.7 \%$ & $-39.4 \%$ \\
\hline
\end{tabular}

Note: $100 \%$ in the table is defined as one under the natural average flow. 


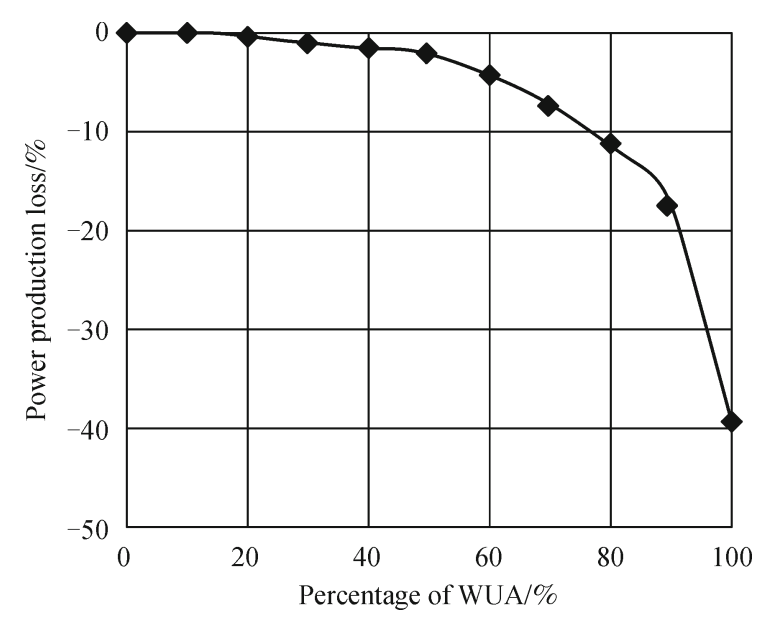

Fig. 4 Relation between percentage of WUA and power production loss.

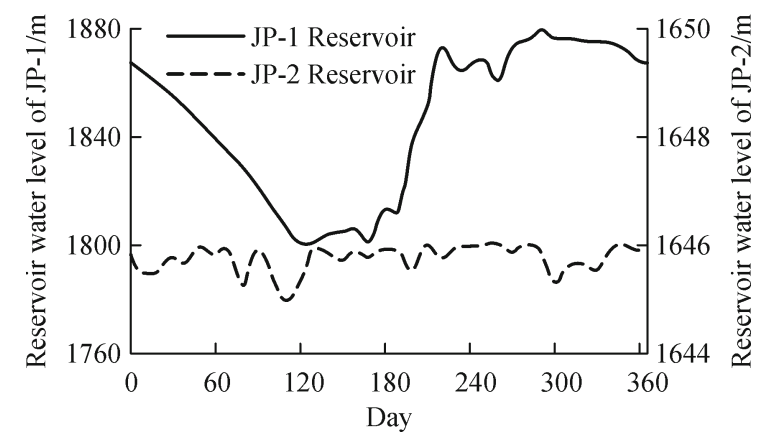

Fig. 5 Operational water levels upstream of the cascaded reservoirs.

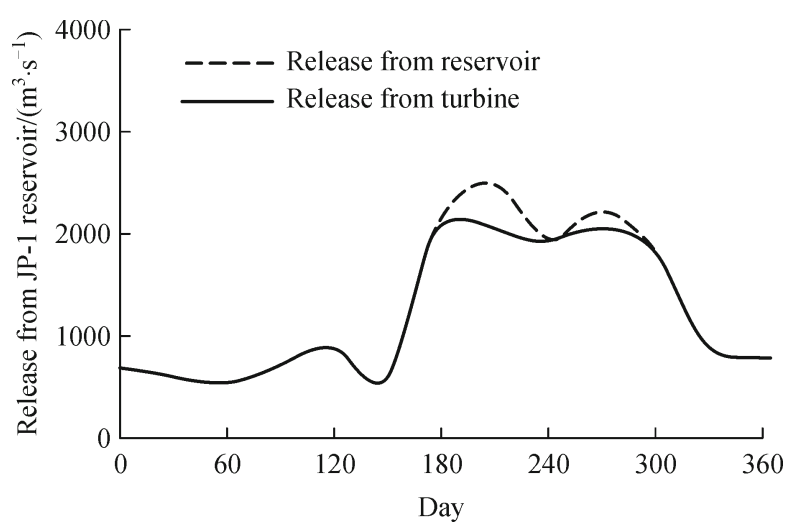

Fig. 6 Discharge from JP-1 reservoir under the proposed operation scheme.

(ECIDI, 2005), the JP cascaded reservoirs start to impound water in May. Therefore, the reservoir water level of JP-1 gradually increases from the dead level $(1,800 \mathrm{~m})$ in early May. It reaches the highest water level $(1,880 \mathrm{~m})$ in early
August, based on the optimization result. This increase is because the natural inflow is larger than the turbine capacity. When the highest water level is reached and the natural inflow is still greater than the turbine capacity, the surplus discharge is released through the spillway of the JP-1 dam. Such a situation occurs in the period from August to October (Fig. 6). The water level is maintained at the highest level until early December in order to maximize hydropower production. From December, the turbined discharge is larger than the inflow, which leads to a gradual decrease of the water level, until the dead water level is reached in the following May (Fig. 5).

The water level of the JP-2 reservoir varies within a small range due to its small regulation capacity (Fig. 5). For the JP-2 reservoir, the inflow is the total discharge from JP-1. During the flood season, the total discharge from the JP-1 reservoir exceeds the turbine capacity of the JP-2 plant (Fig. 7). The surplus flow routed by the JP-2 reservoir is released into the Dahewan reach through the spillway.

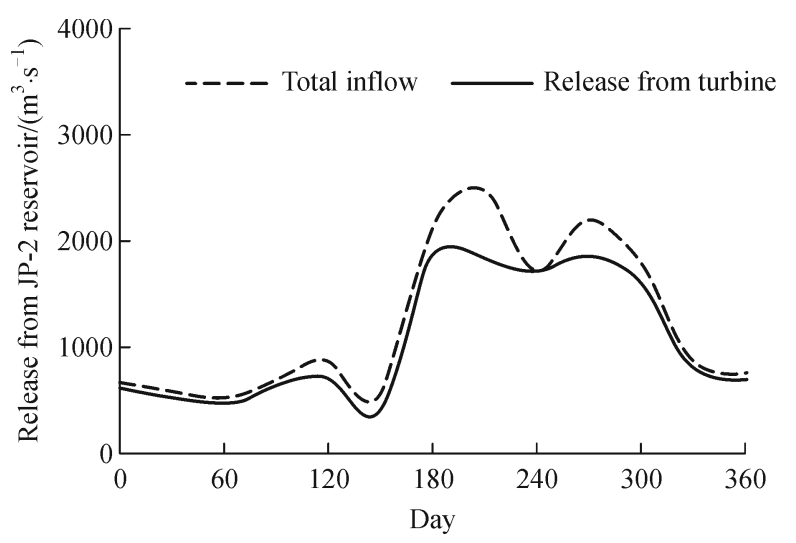

Fig. 7 Discharge from JP-2 reservoir under the proposed operation scheme.

\subsection{Discussion of the hydrograph for the Dahewan Reach}

The hydrograph for the Dahewan Reach under the recommended operation scheme is compared with EFRs in Fig. 8. In the dry season, the release is identical with the EFR constraint, varying from $36 \mathrm{~m}^{3} / \mathrm{s}$ to $50 \mathrm{~m}^{3} / \mathrm{s}$. Under this condition, the river is about $58 \mathrm{~m}$ wide, and the depth is between $1.4 \mathrm{~m}$ and $9.5 \mathrm{~m}$, maintaining a middle-sized river feature. The width and depth are more than three times the size of the fish, implying that the basic requirements of the fish, in terms of moving and food searching, can be satisfied (ECIDI, 2005). During the flood season, an additional flow, with a maximum of $640 \mathrm{~m}^{3} / \mathrm{s}$, appears in the Dahewan Reach due to the release of surplus water from the reservoirs. The average water depth will increase by $2 \mathrm{~m}$, and the average river width reaches to $60 \mathrm{~m}$, in keeping with the characteristics of a large river. 


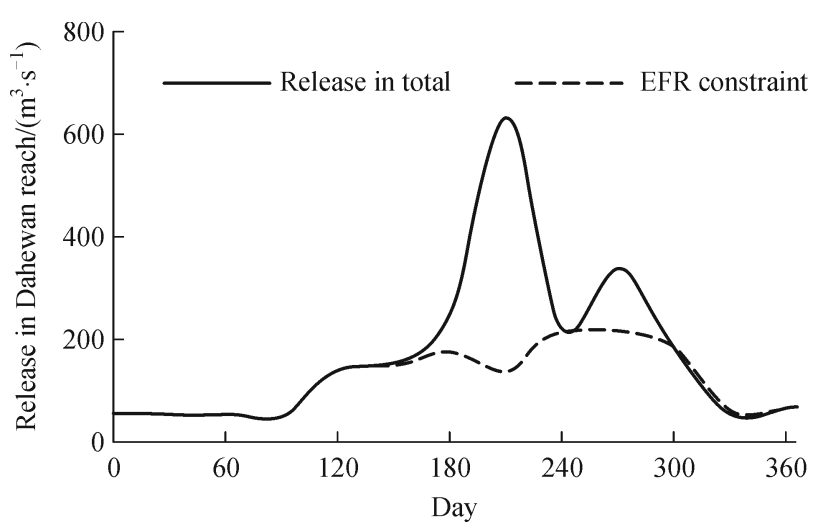

Fig. 8 Discharge in the dewatered river reach under proposed operation scheme.

\section{Conclusions}

JP-2 is a diversion type power plant that transfers water through four tunnels. As a consequence, the natural river reach is dewatered. To mitigate adverse impact, the operation of the JP cascaded reservoirs needs to consider ecological flow requirements in the reach, in order to maintain the integrity of the specific river ecosystem. The present study specifically aims to protect the spawning and over-wintering grounds of $S$. chongi fish. The dedicated release of water will lead to hydropower production loss. This study applies both Tennant method and habitat method to determine ecological hydrographs corresponding to different ecological conservation levels, and develops an optimization model to explore possible trade-off solutions. The results show that, using the Tennant method, the loss rate of hydropower production increases gradually with habitat improvement of the management target. Using the habitat method, a knick point can be found that achieves a 50\% WUA conservation level at the expense of only a $2.5 \%$ hydropower production loss. The latter is recommended as the practical scheme for the ecologically-friendly operation of the JP cascaded reservoirs. Under the recommended scheme, the discharges into the Dahewan river reach are in the range of $36-50 \mathrm{~m}^{3} / \mathrm{s}$ during the dry season.

$S$. chongi is only one of the many fish species of the Yalongjiang River. Hence, similar modeling needs to be conducted for other important fish species, which includes the habitats needed by them for spawning and early stages of growth. Moreover, model parameters should be iteratively adjusted based on field observations. The effects of dam operation on the thermal regime of river water, on water quality, and on sediment conditions, should be modeled and monitored. With such additional efforts, the long-term conservation of the affected river ecosystem can be achieved.

Acknowledgements The authors are grateful for the financial support of the National Basic Research Program of China (No. 2010CB429004), the
National Natural Science Foundation of China (Grant Nos. 51279196 and 51109012), the Public Welfare Project (201101005), and the '100 Talent Program of Chinese Academy of Sciences (A1049)'. Great appreciations are expressed to the anonymous reviewers for the valuable comments and careful corrections.

\section{References}

Bovee K D (1982). A Guide to Stream Habitat Analyses Using the Instream Flow Incremental Methodology. Instream Flow Information. Washington: US Fish and Wildlife Service, 67-73

Castelletti A, Pianosi F, Soncini-Sessa R (2008). Water reservoir control under economic, social and environmental constraints. Automatica, 44(6): 1595-1607

Chen B, Chen G, Hao F, Yang Z (2009). Exergy-based water resource allocation of the mainstream Yellow River. Commun Nonlinear Sci Numer Simul, 14(4): 1721-1728

Chen D, Huang G, Chen Q, Jin F (2010). Implementing Eco-friendly reservoir operation by using genetic algorithm with dynamic mutation operator. Lect Notes Comput Sci, 6330: 509-516

Chen Q, Chen D, Han R, Li R, Ma J, Blanckaert K (2012). Optimizing the operation of the Qingshitan Reservoir in the Lijiang River for multiple human interests and quasi-natural flow maintenance. J Environ Sci (China), 24(11): 1923-1928

Chen Q, Chen D, Li R, Ma J, Blanckaert K (2013). Adapting the operation of two cascaded reservoirs for ecological flow requirement of a de-watered river channel due to diversion-type hydropower stations. Ecol Modell, 252: 266-272

ECIDI (2005). Report of Environmental Impact Assessment on JinpingII Hydropower Project. Hangzhou: East China Investigation and Design Institute (in Chinese)

Homa E S, Vogel R M, Smith M P, Apse C D, Huber-Lee A, Sieber J (2005). An optimization approach for balancing human and ecological flow needs. In: EWRI 2005: Impacts of Global Climate Change, Proceedings of the 2005 World Water and Environmental Resources Congress, Anchorage, Alaska

Jager H I, Rose K A (2003). Designing optimal flow patterns for fall chinook salmon in a Central Valley river. N Am J Fish Manage, 23 (1): $1-21$

Labadie J W (2004). Optimal operation of multi-reservoir systems: stateof-the-art review. J Water Resour Plan Manage, 130(2): 93-111

Li R, Chen Q, Chen D (2011). Ecological hydrograph based on Schizothorax chongi habitat conservation in the dewatered river channel between Jinping Cascaded Dams. Science China, 54(S1): 54-63

Mei Y, Yang N, Zhai Y (2009). Optimal ecological sound operation of the cascade reservoirs in the lower Yalongjiang River. Advances in Water Science, 20(5): 721-725 (in Chinese)

Reiser D W, Wesche T A, Estes C (1989). Status of instream flow legislation and practices in North America. Fisheries (Bethesda, Md), 14(2): 22-29

Renöfält B M, Jansson R, Nilsson C (2010). Effects of hydropower generation and opportunities for environmental flow management in Swedish riverine ecosystems. Freshw Biol, 55: 49-67

Richter B D, Baumgartner J V, Wigington R, Braun D P (1997). How much water does a river need? Freshw Biol, 37(1): 231-249 
Shiau J T, Wu F C (2006). Compromise programming methodology for determining instream flow under multi objective water allocation criteria. J Am Water Resour Assoc, 42(5): 1179-1191

Smith B T, Jager H I, Sale M J (2007). Optimization of Hydropower Resources: Current Practices and Opportunities for Improvement. ORNL/TM-2006/91. Oak Ridge National Laboratory

Suen J P, Eheart J W (2006). Reservoir management to balance ecosystem and human needs: incorporating the paradigm of the ecological flow regime. Water Resour Res, 42(3): W03417

Tennant D L (1976). Instream flow regimens for fish, wildlife, recreation, and related environmental resources. In: Orsborn J F, Allman C H, eds. Proceedings of the Symposium and Speciality Conference on Instream Flow Needs II. American Fisheries Society, Bethesda, Maryland, 359-373

Tharme R E (2003). A global perspective on environmental flow assessment: emerging trends in the development and application of environmental flow methodologies for rivers. River Res Appl, 19(56): $397-441$

Tu Z, Yuan X, Han J, Shi X, Huang Y, Johnson D (2011). Aerobic swimming performance of juvenile Schizothorax chongi (Pisces, Cyprinidae) in the Yalong River, southwestern China. Hydrobiologia, 675(1): 119-127
Wang J, Guo X (2011). The ecological water demand reducing reach of Yalong river downstream of Jinping waterpower station calculated based On R2CROSS. Jilin Water Resources, 351(8): 25-28 (in Chinese)

Wang S (2004). Discussion on dam and ecosystem. Hydropower, 30(4): 1-4 (in Chinese)

Whiting P J (2002). Stream flow necessary for environmental maintenance. Annu Rev Earth Planet Sci, 30(1): 181-206

Wohl E, Angermeier P L, Bledsoe B, Kondolf M, MacDonnell L, Merritt D M, Palmer M A, Poff N L, Tarboton D (2005). River restoration. Water Resour Res, 41(10): WR003985

Wurbs R A (1993). Reservoir-system simulation and optimization models. J Water Resour Plan Manage, 119(4): 455-472

Yang Z, Sun T, Cui B, Chen B, Chen G (2009). Environmental flow requirements for integrated water resources allocation in the Yellow River Basin, China. Commun Nonlinear Sci Numer Simul, 14(5): 2469-2481

Yeh W (1985). Reservoir management and operation models: a state-ofthe-art review. Water Resour Res, 21(12): 1797-1818

Yin X, Yang Z (2011). Development of a coupled reservoir operation and water diversion model: balancing human and environmental flow requirements. Ecol Modell, 222(2): 224-231 